\title{
Hand to Hand
}

Susanna E. Bedell, MD, FACP, and Thomas B. Graboys, MD, FACP

Examination of the hands has the potential to transform the encounter between physician and patient. Taking the hands conveys a sense of warmth and connectedness and is a means to communicate the physician's mindfulness. The hands can focus the examination on the individual patient as a complete human being, and not merely a disease or a collection of symptoms. The hands provide readily accessible information that may not be available through other evaluations, and they offer clues to a patient's physical and mental health. Commonplace observations, such as those revealed in the hands, can unravel medical mysteries and provide profound clinical insights.

KEY WORDS: examination of the hands; scientific and medical. J GEN INTERN MED 2002;17:654-656.

A physician's examination of the patient's hands unveils simple, readily accessible information that provides an understanding about the patient often not available through any other means. Because the initial physical encounter between doctor and patient can also do much to relieve anxiety, we suggest the examination begin with the hands. Taking the hands can be familiar and reassuring. Hands have a story all their own, and searching for their secrets can also do much to remedy patients' perspective that doctors are "cold and aloof." 1 The hands are one legend to a patient's life and a key to the doctor's discovery of occult disease. ${ }^{2}$ Commonplace observations about the hands can unravel medical mysteries and yield profound clinical insights. At first, some observations may seem trivial, but searching for them strengthens our diagnostic skills and guides us in a more focused and intelligent management of patients. Finally, the hands may play an important role as a cue for physicians to assume a mindful presence with their patients.

\section{TAKING THE HANDS: THE HANDSHAKE}

In the course of a patient's visit to the doctor, there are 3 encounters with the hands: the salutary handshake, the examination of the hands, and the parting handshake. All 3 have the potential to transform the doctor's encounter with the patient, and they provide an opportunity for the

Received from Lown Cardiovascular Center and Harvard Medical School

Address correspondence and requests for reprints to Dr. Bedell: 21 Longwood Ave., Brookline, MA 02446. doctor to assure a patient that he will be well taken care of. For the patient, the familiar association of comfort with holding a hand establishes a reassuring context for the examination. It dispels the perception of indifference and distance, and it is a reminder to both physician and patient that the setting for the physical examination is humane. If the transition from hands to other elements of the physical exam is gradual, the doctor can move gently up to the neck in a logical, nonthreatening sequence, rather than rushing to the patient's neck to feel for lymph nodes or thyroid.

What the hands have to offer begins with the handshake. When the patient enters the office, the handshake is a trust-building act and a prologue to history taking. During an introductory handshake, the doctor can signal the start of a humane relationship between equals if the handshake conveys sincerity and warmth. This initial handshake can also convey to the doctor clues about the patient's illness, character, or psychologic state. Is the patient's palm warm and moist, suggesting hyperthyroidism? Does the patient pause in the process of a firm handshake to greet the doctor with enthusiasm and confidence? Or does the patient's hand feel limp? Does the patient withdraw before the greeting is complete?

The handshake may also signal the end of the medical encounter. When the doctor has completed a visit with the patient, the handshake becomes a friendly indication that the appointment has ended. It can be a warm reaffirmation of the human exchange that has occurred, of the physician's connectedness to the patient, and of the emotional bond that may attend every doctor/patient relationship.

\section{TAKING THE HANDS: SECRETS REVEALED IN THE EXAMINATION}

Of the 3 takings of the hands, it is the examination that can be most telling.

Examination of the hands is as much a science as an art. Many secrets to a patient's symptoms or illnesses are revealed through the hands. In a matter of seconds, the doctor can find out whether the patient has attempted suicide or suffers from debilitating arthritis. An initial glance at the hands offers insight into the patient's lifestyle or hobbies and reveals whether the patient spends hours in the garden or at the beauty parlor. This information can also bring to the physician's attention common points of interest with the patient.

The hands offer clues to systemic disease involving any organ system. The opportunity for the doctor to learn from 
the evaluation of the hands suggests that a perfunctory pause for this part of the physical examination is inadequate. Signals from the hands can aid in the diagnosis of diseases associated with arachnodactyly, Dupuytren's contractures, Osler's nodes, palmar erythema or sclerodactyly, among many other specific findings found on the hands. ${ }^{2,3}$

Patterns of joint involvement may clarify the diagnosis for a patient who complains of joint pain. Arthritis of the metacarpophalangeal joints, for example, is more likely to be rheumatoid arthritis than osteoarthritis. No other single part of the examination offers as many general clues to both underlying systemic diseases and to a specific diagnosis for inflammatory joint disease.

Similarly, careful attention to nail beds may also provide important clues to an underlying diagnosis. Observing Terry's nails, clubbing, or Beau's lines directs the observer to search for an underlying systemic illness, while pitting of the nails focuses the diagnosis on a specific form of inflammatory arthritis, psoriatic arthritis. ${ }^{4}$

The concept that the hand serves as more than an appendage for salutation is not a new one. In his masterpiece, The Principles and Practice of Medicine, Olser details how an early twentieth-century physician found associated illnesses and implications of Heberden's nodosities. "The subjects may be in perfect health, though more commonly they have digestive troubles, neuralgia or rheumatic pains, or have had gout... The condition is not curable; but there is this hopeful feature-the subjects of these nodosities rarely have involvement of the larger joints. They have been regarded, too, as an indication of longevity." ${ }^{5}$ As Osler suggests, the simple act of examining the patient's hands readily divulges features of the person's history. Taking hold of the hands is reminiscent of years gone by when the Oslerian model of patient observation was de rigueur.

Examination of the hands is also a valuable way to teach students the introduction to the physical exam. Observational skills reap rich rewards when applied to the vase information the hands offer an alert and educated observer. Similarly, the patient's response to the careful examination of the hands is a teaching tool. While the doctor holds a patient's hands, the patient often expresses curiosity and reassurance that the doctor is mindfully checking all the clues available to establish a diagnosis. When the doctor makes a comment about the hand, how much has the patient already noticed, and what is the response? These reactions may reflect whether a patient is observant or anxious. Examination of the hand frequently prompts patients to ask, "What are you looking for?" This allows for a gentle entrée with the patient for clues of personality, life style, and disease. One of our patients "excused" himself because of "sweaty palms," while another patient indicated that it "made me feel cared for" when the physician held his hands "before examining the rest of my body."

During the examination, the patient may also reveal parts of the history initially withheld. After scars of the volar surface of the wrist of a 30-year-old woman were noted, she shared the story of her suicidal struggle with anorexia. Her remoteness was dissipated by a simple observation about her lifelong secret.

\section{Mindfulness}

Taking the hands is more than a simple ritualistic act. It establishes a context that can encourage the doctor to achieve an active, undistracted focus on the patient. Examination of the hands can become a safe place for the doctor to pause, establish an inquiring mindset, and experience focused critical self-reflection. ${ }^{6}$

Taking the hands may be the physician's cue for mindfulness, one means of establishing a conscious, engaged presence with the patient. Examination of the hands invites openness to what the patient is like as a person, not just as a compilation of symptoms and signs. When there is a moment of silence as the doctor holds and observes the patient's hands, it suggests to the patient that the doctor has all the time in the world to learn about the person as she searches for clues to diagnose illness.

Mindfulness presents a personal challenge for the physician, a trigger for curiosity about what personal and physiologic features the hand may uncover. Because so much that the hands have to reveal is evident by simple observation, the hands offer a unique opportunity for the physician to become focused. By transforming the physical examination into an attentive process, the physician may become totally engaged with the patient and his state of mind. As Anatole Broyard said, “I wouldn't demand a lot of my doctor's time. I just wish he would brood on my situation for perhaps 5 minutes, that he would give me his whole mind just once, be bonded with me for a brief space, survey my soul as well as my flesh to get at my illness, for each man is ill in his own way .... Just as he orders blood tests and bone scans of my body, I'd like my doctor to scan me, to grope for my spirit as well as my prostate. Without some such recognition, I am nothing but my illness."7 Unlike other suggestions for ways to attain mindfulness, examination of the hands does not require extensive commitments to outside activities, such as the practice of meditation, that physicians may not have time to undertake. ${ }^{4}$ Learning to carefully examine the hands offers on-the-job training for mindfulness that is fundamentally personal and individualized. ${ }^{6}$

In an era in which time is at a premium in medicine, it becomes more important than ever that physicians adhere to an efficient practice and remain fully focused on the patient at the time of the history and physical examination. In the busy routine of daily practice, doctors may fail to notice what is right in front of them, so that details are forgotten even before the examination is concluded. How many doctors can recount times when they have gone through a physical examination, and by the end, have forgotten the quality of the second heart sound or whether there was an ecchymosis on the chest? Becoming fully 
focused on the patient may make the doctor more efficient, thus really allowing more time for a patient's questions or concerns. Routinized thinking, which so easily governs medical practice, is the opposite of mindfulness. ${ }^{8}$ Taking the hands can help the doctor avoid such routinzied thinking.

\section{CONCLUSION}

Multiple studies have shown that encounters between primary care physicians and their patients average 16 minutes. $^{9}$ Such limitations require the physician to learn how to complete a focused physical examination. Comprehensive examination of the hands may not take more than a minute.

The rhetoric of cost-effective medical management is often counter-balanced by pleas of caring. How do we translate these well-intentioned words into action? What specific guidelines can we give our students and ourselves to promote humanistic medicine ${ }^{10,11}$ We believe that a careful examination of the hands may be one route to this end. Beginning the examination with the hands establishes a personal connection with the patient and reinforces the trust between physician and patient that was initiated during the history. It opens the possibility for an equal exchange between doctor and patient as both observe and talk about the hands. It is a simple, accessible, comforting, and informative technique that combines the art and science of medicine with minimal time and no risk or cost for our patients. For the mindful physician, important clues to diseases in any organ system are present in the hands.

We suggest that beginning the physical examination by holding and exploring the patient's hands is a logical entrée into the mysteries of the human condition and body. The symbolic connection of the patient and the physician is at once understood by taking the patient's hand. This revealing, nonthreatening act is an indication of the privilege of being a physician.

We would like to thank Peter Zheutlin for his thoughtful review of this manuscript.

This work was supported by a grant from Bay State Federal Savings Bank and The Lown Cardiovascular Research Foundation, 21 Longwood Ave., Brookline, Mass.

\section{REFERENCES}

1. Cherkin DC, Deyo RA, Battie M, Street J, Barlow W. A comparison of physical therapy, chiropractic manipulation and provision of an educational booklet for the treatment of patients with low back pain. N Engl J Med. 1998;339:1021-9.

2. Silverman ME, Hurst JW. The heart and the hand. Am J Cardiol. 1968;22:718-28.

3. Koopman WJ. Arthritis and Allied Conditions. A Textbook of Rheumatology. Baltimore, Md: Williams and Wilkins; 1997:87778, 1848-51, 1991-93.

4. Fitzpatrick TB, Eisen AZ, Wolff K, Freedberg IM, Austen KF. Dermatology in General Medicine, Textbook and Atlas. New York: McGraw-Hill; 1987:470-471, 652-654, 1956-1957.

5. Olser W. The Principles and Practice of Medicine. New York: D. Appleton and Company; 1892:284.

6. Epstein RM. Mindful practice. JAMA. 1999;282:833-9.

7. Broyard A. Doctor talk to me. The New York Times Magazine. August 26, 1990:17.

8. Langer EJ. Mindfulness. New York: Addison-Wesley Publishing; 1989:35-41.

9. Braddock CH, Edwards KA, Hasenberg NM, Laidley TL, Levinson W. Informed decision making in outpatient practice: time to get back to basics. JAMA. 1999;282:2313-20.

10. Medical School Objectives Writing Group. Learning objectives for medical student education - guidelines for medical schools: report 1 of the Medical Schools Objective Project. Acad Med. 1999;74:13-8.

11. Swick HM, Szenas P, Danoff D, Whitcomb ME. Teaching professionalism in undergraduate medical education. JAMA. 1999;282: 830-32. 